\title{
Effects of mechanical operation-induced root injury on maize growth and yield
}

\author{
Hong $\mathrm{Hu}^{1 *}$, Junfeng $\mathrm{GaO}^{2}$, Jie Wu${ }^{1}$, Yijin Mao ${ }^{3}$, Jingzhu $\mathrm{Lu}^{1}$, Qingtao $\mathrm{Li}^{1}$ \\ (1. Institute of Modern Agricultural Equipment, Xihua University, Chengdu 610039, China; \\ 2. Lincoln Agri-Robotic Centre, Lincoln Institute for Agri-Food Technology, University of Lincoln, Lincoln, LN6 7TS, UK; \\ 3. Shenzhen Escope Technology Co., Ltd., Shenzhen 518052, Guangdong, China)
}

\begin{abstract}
A 2-year field experiment was conducted in 2015 and 2016 by using artificial root pruning to simulate mechanical root injury caused by agricultural machinery components and reveal its effects on maize growth and yield. Quasi-level orthogonal experimental design was employed to create orthogonal tables with four factors of interest, namely, pruning time (jointing stage, JS; big trumpet period, BTP), pruning method (unilateral pruning, UNP; bilateral pruning, BIP), pruning distance $(5,10$, and $15 \mathrm{~cm})$ and pruning depth $(5,10$, and $15 \mathrm{~cm})$. Results revealed that 1) maize growth was inhibited at the beginning of root pruning; 2) stem diameter (SD) and plant height (PHE) were smaller than those of the control check (CK) but exceeded the latter after $20 \mathrm{~d}$ of root pruning in JS; 3) SD and PHE were always smaller than those of the CK under root pruning in BTP; 4) $\mathrm{T}_{8}$ (BTP, BIP, $5 \mathrm{~cm}$ of pruning distance and $15 \mathrm{~cm}$ of pruning depth) can reach to a significant level $(p<$ 0.01). The vertical distribution and total dry weight (TDW) of maize roots in soil were affected by different root pruning treatments. When pruning in JS, the root ratio in $0-10 \mathrm{~cm}$ soil was $11.6 \%$ in $\mathrm{T}_{2}$ (JS, UNP, a pruning distance of $10 \mathrm{~cm}$ and pruning depth of $10 \mathrm{~cm}$ ). When pruning in BTP, the root ratio of $10-20 \mathrm{~cm}$ soil layer increased by $15 \%$. However, the TDW of maize decreased, the largest of which occurred in $\mathrm{T}_{8}$ at $53 \%$. With the exception of a $0.43 \%$ increase in $\mathrm{T}_{3}$ (JS, UNP, $15 \mathrm{~cm}$ of pruning distance and $15 \mathrm{~cm}$ of pruning depth), the maize yield of all other treatments decreased compared with that of CK, and the largest reduction was in $\mathrm{T}_{8}$ at up to $19.1 \%$. This finding suggests that a small pruning distance and a large pruning depth greatly influence the growth and yield of maize before and during pruning in BTP. The influence of BIP is greater than that of UNP. These results provide evidence for the effects of mechanical root injury on maize growth and yield and serve as a reference for the selection of mechanical topdressing parameters.
\end{abstract}

Keywords: maize, root pruning, growth, grain yield, mechanical operation-induced injury DOI: $10.25165 /$ j.ijabe.20211406.5079

Citation: Hu H, Gao J F, Wu J, Mao Y J, Lu J Z, Li Q T. Effects of mechanical operation-induced root injury on maize growth and yield. Int J Agric \& Biol Eng, 2021; 14(6): 47-53.

\section{Introduction}

The crop root system plays some critical roles in support, fixation, absorption, composition, and storage during plant growth, and which is the absorptive and metabolic organ of a plant, and displays sensitive reactions to external environmental conditions ${ }^{[1-6]}$ Consequently, its growth affects the development of other organs and determines the growth status of the whole plant ${ }^{[7]}$. Therefore, the growth situation of the root system could be a direct indicator reflecting general information on crop growth and yield ${ }^{[8,9]}$.

Changes in root morphology and structure will lead to changes in the biomass accumulation of the overground part of crop and the utilization efficiency of water and fertilizers, thus ultimately

Received date: 2019-04-15 Accepted date: 2021-11-04

Biographies: Junfeng Gao, $\mathrm{PhD}$, Assistant Professor, research interest: agri-robotics, Email: jugao@lincoln.ac.uk; Jie Wu, PhD, Associate Professor, research interest: mechanical transmission and control, Email: jiewu09323@ mail.xhu.edu.cn; Yijin Mao, $\mathrm{PhD}$, research interest: computational fluid mechanics, Email: ymao.mu@gmail.com; Jingzhu Lu, PhD, Associate Professor, research interest: machine vision and image processing technology, Email: lujingzhu1103@163.com; Qingtao Li, PhD, Associate Professor, research interest: new type of transmission, Email: liqingtao@mail.xhu.edu.cn.

*Corresponding author: Hong $\mathbf{H u}, \mathrm{PhD}$, Lecture, research interest: agricultural mechanization technology and equipment in hilly and mountainous areas. Institute of Modern Agricultural Equipment, Xihua University, Chengdu 610039, China. Tel: +86-28-87723323, Email: huhong@mail.xhu.edu.cn. altering the crop yield ${ }^{[10,11]}$. In general, physical injury, soil movement around the root system, gnawing animals, and root diseases are the main reasons for root morphological and structural changes. Among these, physical injury and the soil movement around the root system are the most important factors ${ }^{[12]}$. In fact, deep loosening, earth-raising, weeding and other intertillage practices will cause physical injury of roots and soil movement around the root system, which directly or indirectly change the root morphology and structure.

To understand the effects of physical injury of roots induced by intertillage practices on crop growth and yield, root pruning method was widely used by researchers. Tests have shown that proper root pruning at appropriate times helps to optimize crop root structure, modulate crop growth and dry matter allocation, and improve water use efficiency and crop yield ${ }^{[13-15]}$. Therefore, root pruning has been used extensively as a cultivation technique in the regulation of aboveground and underground plant sections to influence the vegetative growth, such as the dwarfing cultivation of fruit trees ${ }^{[16,17]}$, the enlargement of tuber biomass ${ }^{[18]}$, and the increasing of stem and leaves biomass of vegetables ${ }^{[19,20]}$. Studies showed that the moisture content in wheat leaves decreases rapidly in a short time after $80 \%$ of primary roots of wheat are excised, but the activities of the remaining root are strengthened to provide adequate moisture uptake and compensate for the missing moisture in wheat leaves ${ }^{[21]}$. When vertically cutting roots at different horizontal distances of summer maize, the photosynthetic of leaves 
was significantly affected, the growth of leaves before anthesis was inhibited, the root shoot biomass and grain yield decreased, the influence degree increases with the decrease of root cutting distance $^{[22]}$. Root pruning for hybrid rice showed that the root length, superficial area, dry matter amount of overground and underground, the nitrogen content of plants, and nitrogen accumulation were inferior to those of rice plants with full roots to a different degree. The decreasing trend persisted when the root pruning amount was increased ${ }^{[23]}$. At the same time, the effects of root pruning on crop growth and yield are different with different pruning times. It is suggested that spring root pruning of winter wheat could promote tillers and spikes, increase photosynthesis of flag leaf after anthesis, improve the seed setting characteristics, and increase grain yield and water use efficiency (WUE) ${ }^{[24]}$. When root pruning at JS, the results showed a reduction in the transpiration rate of wheat leaves and tillers, an increase in the WUE, a delay in the senility of late stage leaves, and prolonged function period when the water supply was sufficient. Ultimately, the grain yield of wheat was increased ${ }^{[25-27]}$. In summary, current studies have proved that root pruning has positive or negative effects on crop growth and yield formation, but the effects were not uniform even for the same crop, and most root studies mainly focused on the effect of a single factor, without considering the combined effects of multiple factors, and most of them are pot experiments.

Maize is an intertillage crop that needs mechanical weeding and topdressing during its growth, and these operations are prone to root injury. This work performed a 2-year investigation of 2015 and 2016 on the effects of root pruning time, pruning method, pruning distance, and pruning depth on maize stem diameter, plant height, total dry weight, and hundred grain weigh through artificial root pruning treatment in the jointing stage (JS) and big trumpet period (BTP) of field maize. This study aimed to determine the effects of mechanical root injury on maize growth and yield and supply a meaningful reference for the selection of mechanical topdressing parameters.

\section{Materials and methods}

\subsection{Sample preparation}

The field experiments were conducted in 2015 and 2016 at Gushanzi Village, Qingyuan Manchu Autonomous County, Fushun City, Liaoning Province, China $\left(125^{\circ} 7^{\prime} \mathrm{E}, 42^{\circ} 11^{\prime} \mathrm{N}, 292 \mathrm{~m}\right.$ above sea level) with the continental monsoon climate type. The mean temperature is $22.8^{\circ} \mathrm{C}$ during the growing seasons of maize, which is 6 months between May and October in 2015 and 2016 when the mean rainfall values are 813 and $790 \mathrm{~mm}$, respectively.

The soil at the experimental station comprises black loam soil that was buried under pine tree seedlings fallowed for 5 years prior to the start of the first cropping period. Soil samples were collected at the upper $30 \mathrm{~cm}$ soil depth. The sampled soil has a $\mathrm{pH}$ value of 7.2 and contains $20.50 \mathrm{~g} / \mathrm{kg}$ organic matter, $0.76 \mathrm{~g} / \mathrm{kg}$ total $\mathrm{N}, 101.4 \mathrm{mg} / \mathrm{kg}$ available $\mathrm{N}, 21.6 \mathrm{mg} / \mathrm{kg}$ available $\mathrm{P}$, and $82.6 \mathrm{mg} / \mathrm{kg}$ rapidly available $\mathrm{K}$.

\subsection{Experimental preparation}

The cultivar of maize adopted in the experiment is 'Jinongyu 409 ' because it is widely planted by farmers in this area and its germination rate is over $95 \%$ with a growth period of 154-161 d. The orthogonal experimental design was employed in the field experiments, and the combined effects of pruning time (JS; BTP), pruning way (unilateral pruning, UNP; bilateral pruning, BIP), pruning distance $(5,10$, and $15 \mathrm{~cm})$, and pruning depth $(5,10$, and
$15 \mathrm{~cm}$ ) on growth and yield of maize were the factors of interest because they are directly affected by mechanical operation. Sample with no pruning treatment was treated as the control check (CK). A multi-factor mixed-level test was performed, and the quasi-level method was adopted to reconstruct the standard $\mathrm{L}_{9}\left(3^{4}\right)$ orthogonal table (Table 1).

Table 1 Orthogonal table of mechanical root pruning test

\begin{tabular}{ccccc}
\hline & \multicolumn{4}{c}{ Factors } \\
\cline { 2 - 5 } Treatments & $\begin{array}{c}\text { Pruning } \\
\text { time }\end{array}$ & $\begin{array}{c}\text { Pruning } \\
\text { method }\end{array}$ & $\begin{array}{c}\text { Pruning } \\
\text { distance/cm }\end{array}$ & $\begin{array}{c}\text { Pruning } \\
\text { depth/cm }\end{array}$ \\
\hline $\mathrm{T}_{1}$ & JS & UNP & 5 & 5 \\
$\mathrm{~T}_{2}$ & JS & BIP & 10 & 10 \\
$\mathrm{~T}_{3}$ & JS & UNP & 15 & 15 \\
$\mathrm{~T}_{4}$ & BTP & UNP & 10 & 15 \\
$\mathrm{~T}_{5}$ & BTP & BIP & 15 & 5 \\
$\mathrm{~T}_{6}$ & BTP & UNP & 5 & 10 \\
$\mathrm{~T}_{7}$ & BTP & UNP & 15 & 10 \\
$\mathrm{~T}_{8}$ & BTP & BIP & 5 & 15 \\
$\mathrm{~T}_{9}$ & BTP & UNP & 10 & 5 \\
\hline
\end{tabular}

Note: JS: Jointing stage; BTP: Big trumpet period; UNP: Unilateral pruning; BIP Bilateral pruning.

Two repetition tests were conducted for each treatment with a total of 20 plots each with $1.5 \mathrm{~m} \times 6.0 \mathrm{~m}$ dimension. Furrows $12 \mathrm{~cm}$ in width and $20 \mathrm{~cm}$ in depth were used to separate each plot. Row spacing was $60 \mathrm{~cm}$, and plant spacing was $25 \mathrm{~cm}$ as shown in Figure 1.

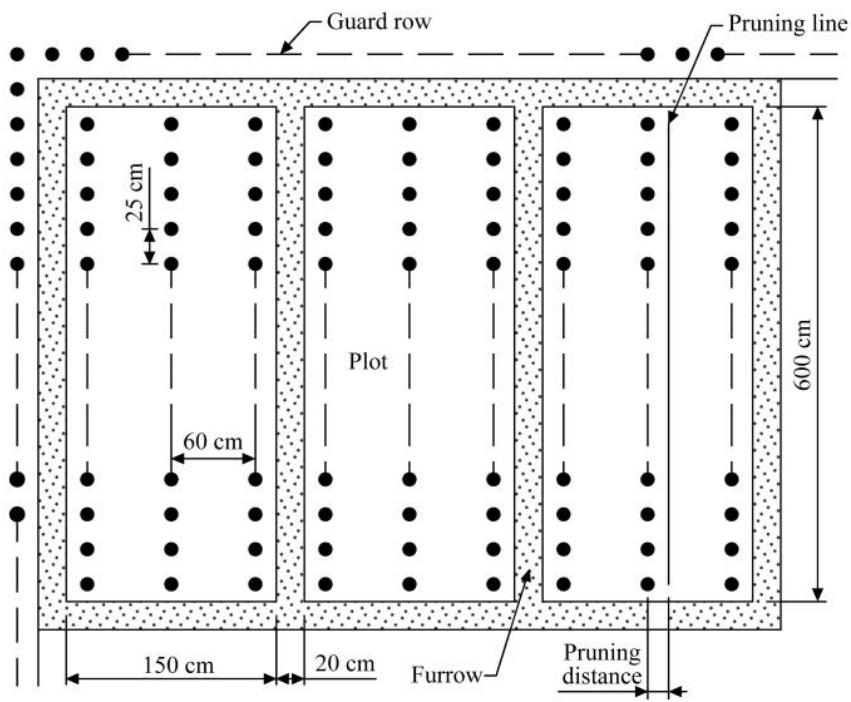

Figure 1 Layout diagram of the test plot

Sowing was conducted on May 8, 2015 and May 7, 2016. Chemical fertilizer (N, P, and $\mathrm{K}$ ) and urea fertilizer were applied at 375 and $150 \mathrm{~kg} / \mathrm{hm}^{2}$, respectively, in BTP. Similar field management measures were adopted for all treatments. Harvesting was performed on October 18, 2015 and October 15, 2016.

\subsection{Experimental methods}

\subsubsection{SD and PHE}

In terms of maize growth situation in the experimental field, June 20 and July 18 were considered as the beginning of JS and BTP, respectively, and were treated as the pruning time. For comparison, the day before JS, namely, June 19, was taken as the first point for data acquisition, which was conducted every $7 \mathrm{~d}$, that is, June 19, June 26, July 3, July 10, July 17, July 24, and July 31.

Five plants with highly similar growth situations were selected by diagonal sampling and marked in each plot. The stem diameter (SD) and plant height (PHE) at the time of interest for each plant 
were measured and recorded during growth. A Vernier caliper was used to measure $\mathrm{SD}$, which is defined as the maximum diameter of the first full outcrop knob. A portable plant height meter named TPYM-G-1 produced by Zhejiang TOP Instrument Co., Ltd. was employed to measure the PHE of sample plants.

\subsubsection{RDW in different soil layers}

Roots surrounded by a cuboid $(30 \mathrm{~cm} \times 30 \quad \mathrm{~cm} \times 45 \mathrm{~cm})$ centering on the maize stalk were collected for root dry weight (RDW) measurement. Based on the soil depth, the roots were cut into pieces and grouped into four layers, namely, 0-10, 10-20, 20-30, and $30-40 \mathrm{~cm}$. The dehydrated weight of roots was measured as follows: 1) the roots were cleaned by wrapping them in a $0.5 \mathrm{~mm}$ nylon mesh bag for deep rinsing; 2) the cleaned roots were dehydrated at a constant temperature of $80^{\circ} \mathrm{C}$ in a dryer until the weight remained constant; 3) weight was measured using an electronic scale $( \pm 0.01 \mathrm{~g})$. The RDW at each soil layer represents the mean weight.

\subsubsection{Grain yield}

Serpentine sampling was employed to predict grain yield in maize harvest, and five ears were chosen for each plot. Ear rows (ERS) and grains per row (GPR) were recorded. Yield or hundred-grain weight $(\mathrm{HGW})$ was obtained after threshing and drying. The yield can be calculated as follows:

$$
Y=(H \times M \times W) / 100000
$$

where, $Y$ is the maize yield, $\mathrm{kg} / \mathrm{hm}^{2} ; H$ is the ear number per hectare of maize; $M$ is the kernels per spike; $W$ is the hundred-grain weight (HGW), g. The value of $H$, in this case, was 67000 as calculated by the spacing of row and plant.

\subsection{Statistical analysis}

Data were presented as mean \pm standard error (SE) in figures. Statistical analysis was performed in IBM SPSS Statistics 19.0, which is widely used for variance analysis and multiple correspondence analysis. Tables were created in Microsoft Excel 2007.

\section{Results}

\subsection{SD and PHE}

The SD and PHE of root-pruned maize plants were smaller than those of non-pruned maize plants, and the differences were dependent on the pruning distance and depth.

The root pruning treatments in JS include $T_{1}, T_{2}$, and $T_{3}$; among which, $\mathrm{T}_{1}$ had a highly significant effect on $\mathrm{SD}(p<0.01$, similarly hereinafter), $\mathrm{T}_{2}$ had less influence on $\mathrm{SD} \quad(p<0.05$, similarly hereinafter), and $\mathrm{T}_{3}$ had no significant influence. The SD values of $T_{1}$ and $T_{2}$ were significantly smaller than that of $C K$ from June 26 to July 10, and no significant change occurred after July 10. Compared with that of CK, the SD of $\mathrm{T}_{1}$ was smaller by $14.4 \%, 10.5 \%$, and $6.1 \%$, and that of $\mathrm{T}_{2}$ was smaller by $12.1 \%$, $8.6 \%$, and $4.9 \%$. $\mathrm{T}_{4}$ to $\mathrm{T}_{9}$ are the root pruning treatments in BTP; among which, $\mathrm{T}_{4}, \mathrm{~T}_{6}$, and $\mathrm{T}_{8}$ had highly significant influences on $\mathrm{SD}, \mathrm{T}_{7}$ and $\mathrm{T}_{9}$ had relatively less significant influence, and $\mathrm{T}_{5}$ did not have significant influence compared with CK. Nevertheless, the degree of influence was weakened after a certain period. According to the results, the ascending order of the SD with different root pruning treatments in BTP was $\mathrm{T}_{8}, \mathrm{~T}_{6}, \mathrm{~T}_{4}, \mathrm{~T}_{9}, \mathrm{~T}_{7}, \mathrm{~T}_{5}$, CK after July 17 (Table 2).

Table 2 Stem diameter in different root cutting treatments $(n=20)$

\begin{tabular}{|c|c|c|c|c|c|c|c|}
\hline \multirow{2}{*}{ Treatment } & \multicolumn{7}{|c|}{$\mathrm{SD} / \mathrm{mm}$} \\
\hline & June 19 & June 26 & July 3 & July 10 & July 17 & July 24 & July 31 \\
\hline $\mathrm{T}_{1}$ & $12.2 \pm 0.5$ & $18.4 \pm 2.3^{* *}$ & $23.0 \pm 1.5 * *$ & $29.0 \pm 0.8^{*}$ & $32.2 \pm 1.4$ & $34.9 \pm 1.4$ & $36.2 \pm 0.9$ \\
\hline $\mathrm{T}_{2}$ & $11.9 \pm 1.2$ & $18.9 \pm 1.5^{*}$ & $23.5 \pm 1.0^{*}$ & $29.4 \pm 1.2^{*}$ & $32.3 \pm 1.6$ & $35.2 \pm 1.3$ & $36.7 \pm 1.4$ \\
\hline $\mathrm{T}_{3}$ & $12.6 \pm 1.0$ & $20.5 \pm 0.4$ & $25.2 \pm 0.5$ & $29.5 \pm 0.6$ & $32.6 \pm 1.0$ & $34.4 \pm 0.8$ & $37.0 \pm 1.1$ \\
\hline $\mathrm{T}_{4}$ & $13.2 \pm 2.4$ & $21.0 \pm 1.0$ & $25.0 \pm 1.6$ & $30.4 \pm 1.5$ & $32.4 \pm 0.6$ & $32.4 \pm 0.9 * *$ & $35.0 \pm 2.1^{*}$ \\
\hline $\mathrm{T}_{5}$ & $11.6 \pm 0.5$ & $20.6 \pm 1.2$ & $26.2 \pm 1.2$ & $30.9 \pm 0.9$ & $31.7 \pm 1.0$ & $33.8 \pm 1.2$ & $35.7 \pm 1.5$ \\
\hline $\mathrm{T}_{6}$ & $10.8 \pm 0.8$ & $22.9 \pm 1.5$ & $25.6 \pm 0.8$ & $29.4 \pm 1.4$ & $33.2 \pm 0.4$ & $32.3 \pm 1.1 * *$ & $34.3 \pm 0.7 * *$ \\
\hline $\mathrm{T}_{7}$ & $11.3 \pm 2.5$ & $21.3 \pm 3.6$ & $26.4 \pm 2.4$ & $30.3 \pm 1.3$ & $31.9 \pm 1.6$ & $33.2 \pm 1.5^{*}$ & $35.6 \pm 1.3^{*}$ \\
\hline $\mathrm{T}_{8}$ & $12.6 \pm 1.2$ & $22.1 \pm 0.9$ & $24.3 \pm 1.2$ & $31.0 \pm 1.6$ & $30.8 \pm 1.0$ & $32.3 \pm 0.9 * *$ & $33.5 \pm 2.0 * *$ \\
\hline $\mathrm{T}_{9}$ & $12.6 \pm 1.8$ & $20.8 \pm 3.2$ & $25.5 \pm 1.0$ & $30.1 \pm 0.4$ & $32.8 \pm 2.2$ & $32.9 \pm 1.2 *$ & $35.1 \pm 1.6^{*}$ \\
\hline $\mathrm{CK}$ & $12.1 \pm 0.8$ & $21.3 \pm 1.1$ & $25.4 \pm 1.6$ & $30.5 \pm 1.8$ & $32.4 \pm 2.4$ & $34.8 \pm 1.7$ & $36.9 \pm 1.5$ \\
\hline
\end{tabular}

Note: $n$ : Number of sampling points; SD: Stem diameter; CK: Control check; * represents a significant difference at the level of 0.05 ; $* *$ represents a highly significant difference at the level of 0.01 ; similarly hereinafter.

The SD of plants with roots pruned in JS was smaller than that of CK before July 17 but returned to normal growth afterward. The SD of plants with roots pruned in BTP was smaller than those of CK and plants with roots pruned in JS after July 17 . The SD of unilaterally and bilaterally pruned plants was smaller than that of $\mathrm{CK}$ all the time after root pruning, and that of bilateral pruned plants was the smallest. The variation trends of SD of the plants with different pruning times, pruning methods pruning distances and pruning depths are shown in Figure 2.

PHE was highly significantly influenced on June 26 and July 3 and significantly influence on July 10 . In addition, $T_{2}$ had a highly significant influence on PHE on June 26 and a significant influence on July 3 , and $\mathrm{T}_{3}$ had no significant influence. The PHE of $T_{1}$ and $T_{2}$ plants were significantly smaller than that of $\mathrm{CK}$ from June 26 to July 17, and no significant change occurred after July 10. Compared with that of CK, the PHE of $\mathrm{T}_{1}$ was smaller by $10.7 \%$,
$8.0 \%$, and $7.9 \%$, and that of $\mathrm{T}_{2}$ was smaller by $8.0 \%, 6.0 \%$, and $5.4 \%$, and the difference was significant. $\mathrm{T}_{4}, \mathrm{~T}_{6}, \mathrm{~T}_{8}$, and $\mathrm{T}_{9}$ had highly significant influences on PHE on July 24 , and $\mathrm{T}_{5}$ and $\mathrm{T}_{7}$ had relatively less significant influences on PHE. On July $31, \mathrm{~T}_{4}, \mathrm{~T}_{6}$, and $\mathrm{T}_{8}$ still had highly significant influences on PHE, $\mathrm{T}_{9}$ had a relatively less significant influence, and $\mathrm{T}_{5}$ did not have significant influence (Table 3).

The PHE of plants with roots pruned in JS was smaller than that of CK before July 17 but matched with that of CK after July 17 Meanwhile, the PHE of plants with roots pruned in BTP was smaller than that of CK and those pruned in JS all the time after July 17 . The PHE of unilaterally and bilaterally pruned plants was smaller than that of CK after July 17, and no significant difference was observed before July 17 . The variation trends of PHE of the plants with different pruning times, pruning methods pruning distances and pruning depths are shown in Figure 3. 


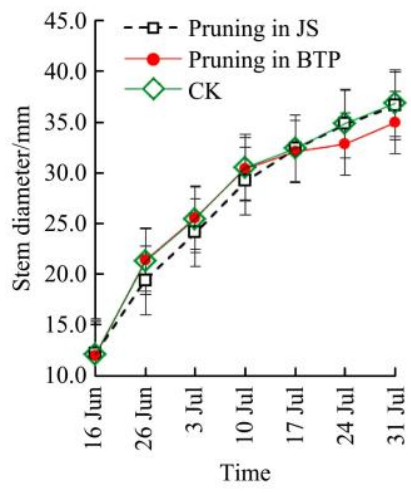

a. SD of plants with different pruning times

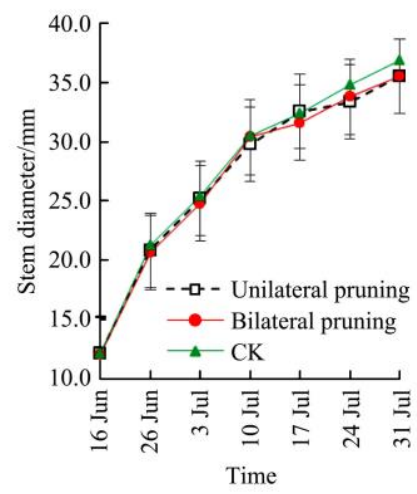

b. SD of plants with different pruning methods

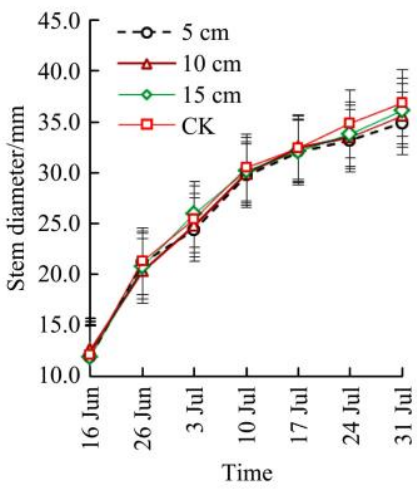

c. SD of plants with different pruning distances

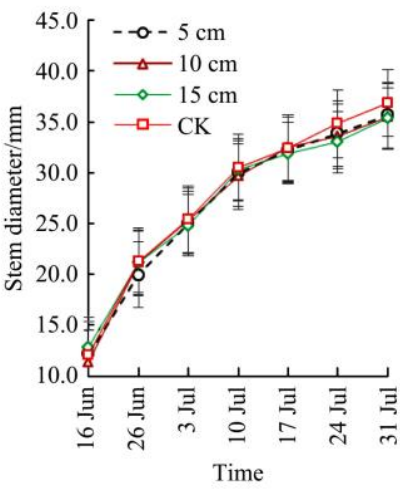

d. SD of plants with different pruning depths

Note: CK: Control check; SD: Stem diameter; JS: Jointing stage; BTP: Big trumpet period.

Figure 2 SD of plants with different root pruning treatments

Table 3 Plant height in different root cutting treatments $(n=20)$

\begin{tabular}{|c|c|c|c|c|c|c|c|}
\hline \multirow{2}{*}{ Treatment } & \multicolumn{7}{|c|}{$\mathrm{PHE} / \mathrm{cm}$} \\
\hline & June 19 & June 26 & July 3 & July 10 & July 17 & July 24 & July 31 \\
\hline $\mathrm{T}_{1}$ & $59.6 \pm 6.4$ & $71.9 \pm 2.0 * *$ & $92.9 \pm 3.1 * *$ & $118.7 \pm 1.6^{*}$ & $179.9 \pm 7.7$ & $242.2 \pm 7.3$ & $322.3 \pm 5.8$ \\
\hline $\mathrm{T}_{2}$ & $62.3 \pm 2.0$ & $74.1 \pm 3.4 * *$ & $94.9 \pm 3.4^{*}$ & $122.0 \pm 3.3$ & $183.2 \pm 9.3$ & $243.9 \pm 5.6$ & $326.4 \pm 7.9$ \\
\hline $\mathrm{T}_{3}$ & $58.1 \pm 1.2$ & $80.8 \pm 4.5$ & $100.8 \pm 4.2$ & $128.8 \pm 3.7$ & $186.6 \pm 3.9$ & $245.6 \pm 6.8$ & $327.2 \pm 9.4$ \\
\hline $\mathrm{T}_{4}$ & $54.9 \pm 5.2$ & $78.4 \pm 4.5$ & $98.2 \pm 3.4$ & $128.3 \pm 4.6$ & $186.1 \pm 7.1$ & $227.3 \pm 6.2 * *$ & $311.6 \pm 6.9 * *$ \\
\hline $\mathrm{T}_{5}$ & $60.9 \pm 3.1$ & $82.1 \pm 1.8$ & $103.2 \pm 5.1$ & $129.0 \pm 6.9$ & $180.4 \pm 2.1$ & $239.2 \pm 8.3^{*}$ & $324.5 \pm 9.3$ \\
\hline $\mathrm{T}_{6}$ & $57.6 \pm 4.9$ & $79.9 \pm 4.8$ & $99.5 \pm 2.4$ & $130.9 \pm 6.7$ & $185.1 \pm 5.1$ & $224.9 \pm 6.4 * *$ & $307.9 \pm 5.4 * *$ \\
\hline $\mathrm{T}_{7}$ & $59.2 \pm 2.1$ & $82.9 \pm 2.6$ & $102.8 \pm 2.6$ & $126.4 \pm 2.7$ & $184.7 \pm 8.7$ & $233.3 \pm 7.7 *$ & $319.5 \pm 7.8^{*}$ \\
\hline $\mathrm{T}_{8}$ & $56.6 \pm 2.8$ & $80.9 \pm 4.4$ & $100.0 \pm 2.1$ & $126.9 \pm 2.3$ & $183.4 \pm 4.5$ & $219.2 \pm 6.3^{* *}$ & $305.0 \pm 6.5 * *$ \\
\hline $\mathrm{T}_{9}$ & $58.8 \pm 4.3$ & $79.0 \pm 3.6$ & $104.1 \pm 3.4$ & $131.9 \pm 5.9$ & $186.2 \pm 5.9$ & $233.7 \pm 8.8 * *$ & $317.8 \pm 9.8^{*}$ \\
\hline $\mathrm{CK}$ & $58.7 \pm 3.5$ & $80.5 \pm 2.9$ & $101.0 \pm 2.4$ & $128.9 \pm 4.7$ & $185.3 \pm 6.2$ & $245.9 \pm 9.6$ & $326.3 \pm 7.9$ \\
\hline
\end{tabular}

Note: PHE: Plant height.

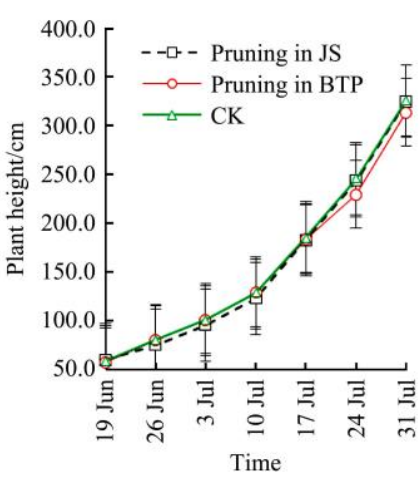

a. PHE of plants with different pruning times

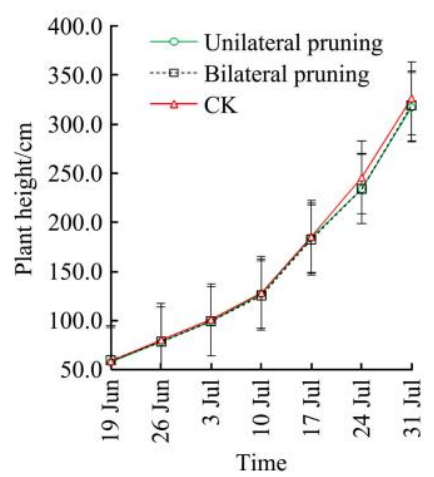

b. PHE of plants with different pruning methods

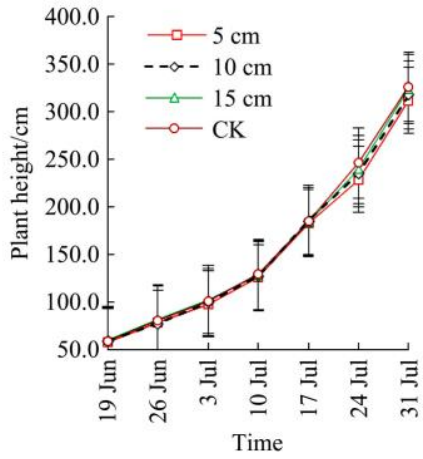

c. PHE of plants with different pruning distances

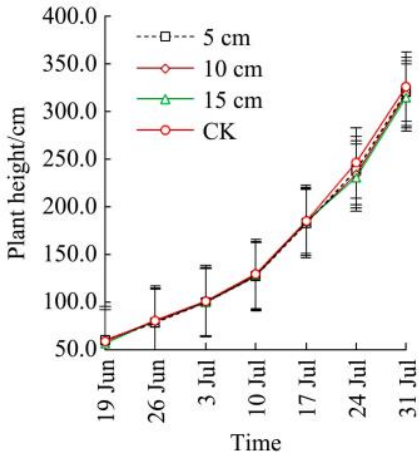

d. PHE of plants with different pruning depths

Figure 3 PHE of plants with different root pruning treatments

\subsection{RDW}

Most roots (90\%) are located at the depth ranging from $0 \mathrm{~cm}$ to $20 \mathrm{~cm}$ soil layer and are rarely found in soil depth of more than $30 \mathrm{~cm}$ (less than 5\%). The total RDW of maize had a small difference among $\mathrm{T}_{1}, \mathrm{~T}_{2}, \mathrm{~T}_{3}, \mathrm{~T}_{5}$, and $\mathrm{CK}$ but was significantly larger than that of $\mathrm{T}_{4}, \mathrm{~T}_{6}, \mathrm{~T}_{7}, \mathrm{~T}_{8}$, and $\mathrm{T}_{9}$. In particular, the descending order of total RDW for all root pruning treatments was $\mathrm{T}_{2}, \mathrm{~T}_{3}, \mathrm{CK}, \mathrm{T}_{5}, \mathrm{~T}_{1}, \mathrm{~T}_{7}, \mathrm{~T}_{9}, \mathrm{~T}_{4}, \mathrm{~T}_{6}, \mathrm{~T}_{8}$. The RDW at depth of 0$10 \mathrm{~cm}$ accounted for $60 \%$ of the total RDW after root pruning in JS, and this value was significantly greater than that for any other soil layer. Therefore, root pruning in JS could promote root growth and increase the root weight/volume in soil layer with a depth of
0-10 cm. In general, the RDW of maize in $0-10 \mathrm{~cm}$ soil layer had minimal difference compared with that of the soil layer with a depth of $10-20 \mathrm{~cm}$ after root pruning in BTP. The RDW in 0$10 \mathrm{~cm}$ soil layer diminished, but that in soil depth of $10-20 \mathrm{~cm}$ increased compared with that of CK. These results showed that the total RDW of maize was generally low in all treatments, and the effects varied according to pruning time and method. Root pruning in JS increased the RDW in $0-10 \mathrm{~cm}$ soil layer by $5 \%$, whereas root pruning in BTP reduced the RDW at $0-10 \mathrm{~cm}$ soil depth but increased it in $10-20 \mathrm{~cm}$ soil layer by $15 \%$. Therefore, root pruning has minimal influence on the RDW of soil layer with more than $20 \mathrm{~cm}$ depth as shown in Figure 4. 


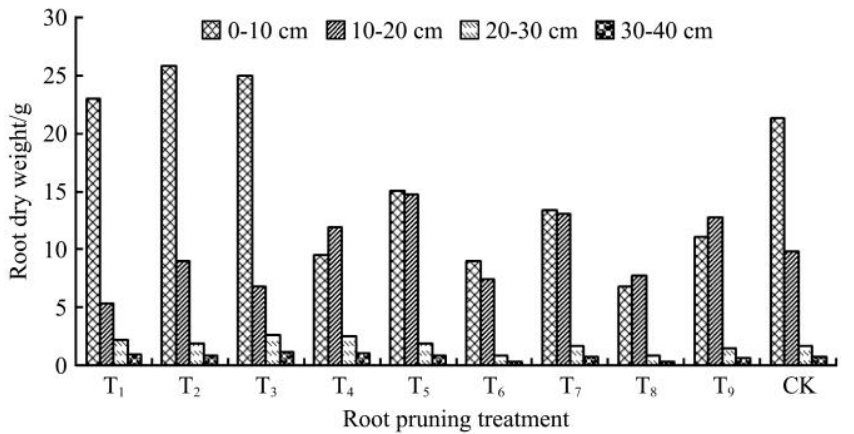

a. RDW of different soil layers with different pruning treatments

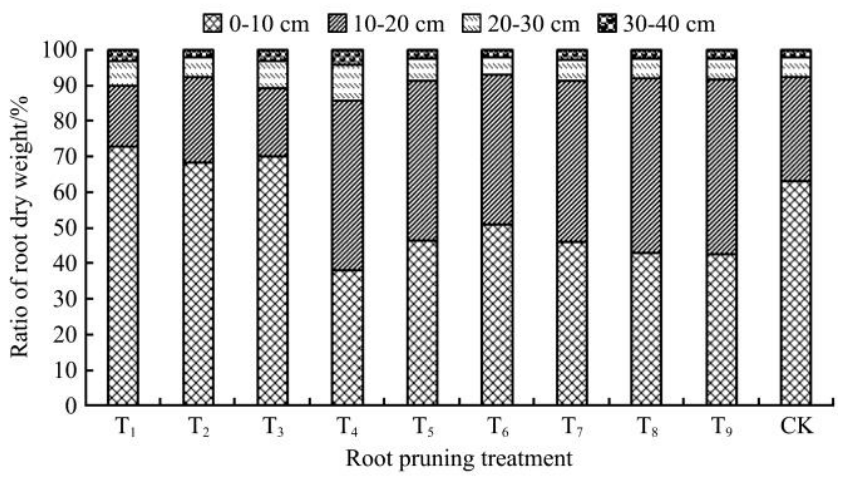

b. $100 \%$ stacked column chart of RDW at different soil layers

Figure 4 RDW of different soil layers

\subsection{Grain yield}

Table 4 indicates that different treatments have various effects on maize yield and yield component. For ear height, no significant difference was observed in $\mathrm{T}_{1}, \mathrm{~T}_{2}, \mathrm{~T}_{3}, \mathrm{~T}_{4}, \mathrm{~T}_{5}, \mathrm{~T}_{7}$, and $\mathrm{T}_{9}$, a significant difference was found in $\mathrm{T}_{6}$ (decreased by $5.6 \%$ ), and highly significant difference was noted in $\mathrm{T}_{8}$ (decreased by $7.7 \%$ ) compared with CK. Maize yield component mainly consists of spike number per hectare, kernels per spike, and HGW. Given that the spike number per hectare depends on the cropping pattern, the maize yield is mainly determined by kernels per spike and HGW. Compared with those of CK, the kernels per spike increased for $T_{1}, T_{2}$, and $T_{3}$ but decreased for the other treatments. A significant difference was found for $\mathrm{T}_{9}$ (decreased by $4.0 \%$ ) and highly significant difference for $\mathrm{T}_{4}$ (decreased by $5.4 \%$ ), $\mathrm{T}_{6}$ (decreased by $7.1 \%$ ), and $\mathrm{T}_{8}$ (decreased by $8.8 \%$ ). Except for $\mathrm{T}_{3}$ (increased by $0.43 \%$ ), the HGW of all treatments decreased, with $\mathrm{T}_{8}$ showing the highest reduction $(19.1 \%)$.

In general, root pruning in JS did not affect ear height and kernels per spike; however, a significant influence on maize yield and kernels per spike occurred when the pruning distance was $5 \mathrm{~cm}$. Root pruning in BTP greatly influenced maize yield and yield component. Therefore, a small pruning distance and a large pruning depth led to low ear height, kernels per spike, HGW, and maize yield (Table 4 ).

Root pruning in JS and BTP lowered the maize yield by $2.89 \%$ and $11.10 \%$, respectively. In addition, the maize yield decreased for the groups with unilateral and bilateral pruning, but the difference was not significant. The influence on maize yield was strengthened when the pruning distance was decreased. The maize yield decreased by $2.90 \%, 9.24 \%$, and $12.96 \%$ at pruning distances of 15,10 , and $5 \mathrm{~cm}$, respectively. The maize yield decreased by $6.39 \%$ and $10.27 \%$ when the pruning depth was 5 and $15 \mathrm{~cm}$, respectively, indicating that a large pruning depth could proportionally reduce the maize yield. $\mathrm{T}_{8}$ had the greatest influence on the maize yield by increasing it to $19.10 \%$ as shown in Figure 5.
Table 4 Maize yield and yield component $(n=20)$

\begin{tabular}{ccccc}
\hline Treatment & Ear height/cm & Kernels per spike & HGW/g & Yield $/ \mathrm{kg} \cdot \mathrm{hm}^{-2}$ \\
\hline $\mathrm{T}_{1}$ & $135.2 \pm 3.8$ & $523.0 \pm 8.5$ & $45.7 \pm 1.1 *$ & $16145 \pm 208^{*}$ \\
$\mathrm{~T}_{2}$ & $135.7 \pm 4.1$ & $526.0 \pm 2.8$ & $46.1 \pm 0.8$ & $16360 \pm 47$ \\
$\mathrm{~T}_{3}$ & $140.5 \pm 3.0$ & $525.0 \pm 17.7$ & $48.3 \pm 1.6$ & $17102 \pm 121$ \\
$\mathrm{~T}_{4}$ & $128.7 \pm 2.1$ & $493.0 \pm 4.9 * *$ & $45.1 \pm 0.8 * *$ & $14967 \pm 243^{*}$ \\
$\mathrm{~T}_{5}$ & $137.9 \pm 6.3$ & $522.0 \pm 12.7$ & $47.3 \pm 0.4$ & $16637 \pm 289$ \\
$\mathrm{~T}_{6}$ & $127.9 \pm 2.3 *$ & $484.0 \pm 9.9 * *$ & $44.5 \pm 1.2^{* *}$ & $14546 \pm 250^{* *}$ \\
$\mathrm{~T}_{7}$ & $132.2 \pm 3.7$ & $520.0 \pm 4.9$ & $45.2 \pm 0.7 *$ & $15864 \pm 258^{*}$ \\
$\mathrm{~T}_{8}$ & $125.1 \pm 4.7 * *$ & $475.0 \pm 8.7 * *$ & $43.0 \pm 1.0^{* *}$ & $13771 \pm 159^{* *}$ \\
$\mathrm{~T}_{9}$ & $129.6 \pm 1.2$ & $500.0 \pm 6.3 *$ & $44.6 \pm 1.6^{* *}$ & $15038 \pm 173 *$ \\
$\mathrm{CK}$ & $135.5 \pm 4.3$ & $521.0 \pm 7.4$ & $48.3 \pm 0.7$ & $17028 \pm 397$ \\
\hline
\end{tabular}

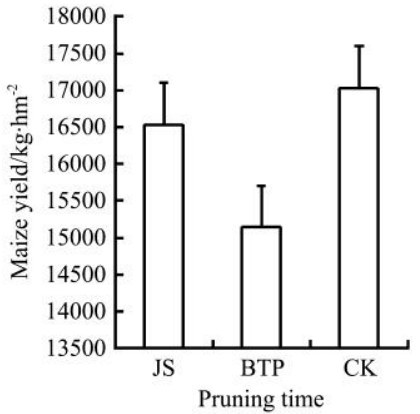

a. Maize yield at different root pruning times

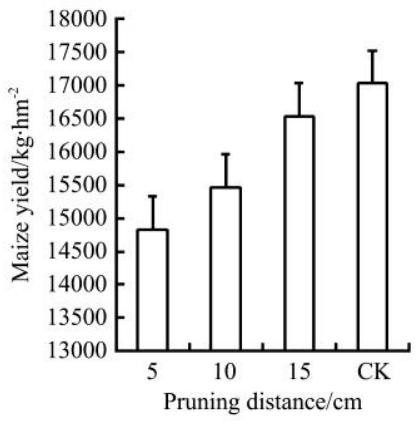

c. Maize yield of different root pruning distances

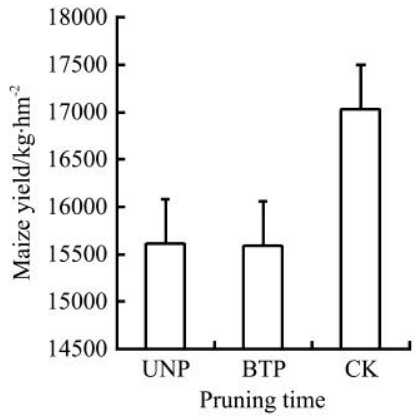

b. Maize yield of different root pruning methods

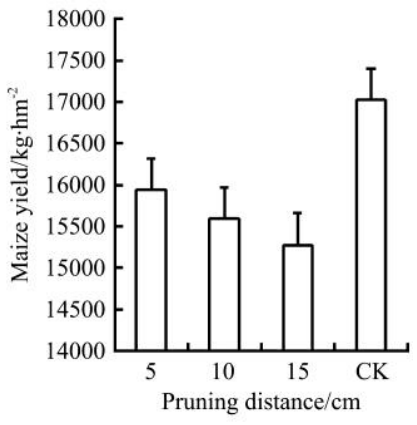

d. Maize yield of different root pruning depths
Figure 5 Maize yield with different root pruning treatments

\section{Discussion}

\subsection{Influence on maize growth}

Many agronomic traits indicate that root pruning can moderately promote crop growth in the seedling stage. Nonetheless, the damage could not be large; otherwise, it could inhibit crop growth ${ }^{[28,29]}$. In general, when root pruning is performed early, the plants could adjust their growth and modulate the resource allocation immediately, and the crops could rapidly return to normal growth ${ }^{[30,31]}$. This finding lays a good foundation for the later robust growth of crop plants. When root pruning is performed late, plant reaction is delayed, and plant is greatly affected $^{[32]}$. Root pruning when the plant is in an important stage directly decreases the supply of water and nutrients for the overground parts of the plant ${ }^{[33]}$. This work revealed that root pruning in JS and BTP influence the SD and PHE of maize to different extents. The SD and PHE are smaller than those of CK at the beginning of root pruning, those of plants root-pruned in JS can recover and even exceed those of CK after some time, and those of plant root-pruned in BTP are consistently lower than those of CK.

The two methods of root pruning to control the SD and PHE of 
maize include inhibition-promotion and inhibition approaches. The former moderately inhibits growth by root pruning in the early stages and then promotes the growth later, and the latter severely prune roots in the early stages or moderately prunes roots in the middle and late stages of maize growth, which are the key phases for maize growth and development. The capability of maize plants to absorb soil water and nutrients diminishes after root pruning; as a response, the photosynthetic efficiency and supply capacity of critical nutrients for the upper part of maize growing are reduced ${ }^{[18,34]}$, thus affecting the thickening or division of maize stem radial cells ${ }^{[35]}$. Ultimately, SD and PHE are affected.

\subsection{Influence on root system}

As a direct physical operation on the root, pruning has a focused effect on the development of root system in the soil at different depths ${ }^{[36]}$. The root system might require a long time to recover after root pruning, hence, maize growth could be inhibited for some time. Given that its compensated growth promotes the germination of secondary root aftermath, the root system could then grow fast and vigorously ${ }^{[18,25,37]}$. The total amount of root system recovers or surpasses that of CK when the total potential of compensating growth exceeds the damage caused by root pruning; however, the total amount of root system could be always lower than that of CK when the total potential is insufficient ${ }^{[38]}$. In this experiment, the total RDW with root pruning in JS does not greatly differ from that of CK but becomes larger than that of CK when the pruning distance is greater than $5 \mathrm{~cm}$. When root pruning occurs in JS, the RDW has the highest value in the $0-10 \mathrm{~cm}$ soil layer and accounts for approximately $70 \%$ of the total RDW, which is $5 \%$ more than that of CK. Nevertheless, the total RDW with root pruning during BTP is generally lower than that of CK, excluding the case with pruning distance of $15 \mathrm{~cm}$. The RDW in 0-10 and $10-20 \mathrm{~cm}$ soil layers are almost identical. Compared with that of $\mathrm{CK}$, the RDW for $0-10 \mathrm{~cm}$ soil layer decreases, whereas that for $10-20 \mathrm{~cm}$ soil layer increases. The test showed that plants form a defensive system against any damage to their own system, such as mechanical injury ${ }^{[39]}$. In long-term co-evolution, mechanical injury on the roots can stimulate their development by growing secondary roots at the injured locations, strengthening metabolism, and achieving self-repair ${ }^{[38,40]}$. Hence, the damage increases the RDW ratio in the $0-10 \mathrm{~cm}$ soil layer during JS. During BTP, the root system beneath the soil surface is already well developed, and pruning could cause larger damage than during JS. The amounts of newly formed secondary roots can be lower than the amount of pruned roots. Meanwhile, the roots in $10-20 \mathrm{~cm}$ soil layer grow rapidly. As a consequence, the RDW ratio in the $0-10 \mathrm{~cm}$ soil layer is diminished, whereas that in $10-20 \mathrm{~cm}$ soil layer increases during BTP. Therefore, the specific rate of change is closely related to the pruning distance and depth.

\subsection{Effect on maize yield}

The growth environment of maize root system is closely related to yield because a large root biomass can yield a high biomass $^{[41]}$. The test indicated that development periods, pruning distances, and pruning depths influence the maize yield at different degrees. When roots are pruned in JS, maize yield is increased by adopting a pruning distance of $15 \mathrm{~cm}$ but is reduced when the distance is less than $10 \mathrm{~cm}$. With the degree of root pruning increased and the root pruning time elapsed, the maize yield decreases severely ${ }^{[42-44]}$. A large root pruning surface, small root pruning distance, deep root pruning depth, and late root pruning time can reduce the yield by a large margin. This result is consistent with previous studies.
BTP is the key period for maize ear formation and determines the seed setting rate of maize ear. When roots are pruned in BTP, the photosynthetic efficiency of leaves decreases, and the capability of absorbing and supplying soil nutrients for ear development diminishes, resulting in low seed setting rate, long baldness, and insufficient maize pellet ${ }^{[45]}$. Consequently, the kernels per spike and HGW of the maize ears could decrease, causing a high reduction in maize yield.

\section{Conclusions}

The effects of root pruning in JS on SD and PHE decreases gradually with maize growth, and the plants recover or exceed normal growth speed after some time. In general, a small pruning distance and a large pruning depth lead to small SD and PHE during root pruning in BTP.

Compared with that of $\mathrm{CK}$, the total RDW is reduced when the pruning distance is reduced, the pruning depth is increased, and the root pruning time is prolonged. The results showed that root pruning in JS increases the proportion of roots in $0-10 \mathrm{~cm}$ soil layer by approximately $5 \%$, whereas root pruning in BTP decreases that in $0-10 \mathrm{~cm}$ soil layer but increases that in $10-20 \mathrm{~cm}$ soil layer by approximately $15 \%$. For soil under $20 \mathrm{~cm}$, the effect of root pruning is negligent.

The field experiment also showed that the maize yield slightly increases during JS when the pruning distance is $15 \mathrm{~cm}$ but reduces when the pruning distance is $10 \mathrm{~cm}$ or less. In addition, the maize yield decreases when root pruning is performed in BTP and could decrease dramatically with the reduced pruning distance and increased pruning depth.

\section{Acknowledgements}

This work was financially supported by the Key Scientific Research Fund of Xihua University (Grant No. Z17121) and Science and Technology Plan Project of Sichuan Provincial (Grant No. 2021TDR0054).

\section{[References]}

[1] Diego T, Federica G, Despoina P, Lorenzo L, Nicola B, Davide B, et al Winter pruning: Effect on root density, root distribution and root/canopy ration in Vitis. vinifera cv. Pinot Gris. Agronomy, 2020; 10(10): 1509. doi: 10.3390/agronomy10101509.

[2] Chilundo M, Joel A, Wesström I, Brito R, Messing I. Response of maize root growth to irrigation and nitrogen management strategies in semi-arid loamy sandy soil. Field Crops Research, 2017; 200: 143-162.

[3] Zhao X H, Yu H Q, Wen J, Wang X G, Du Q, Wang J, et al. Response of root morphology, physiology and endogenous hormones in maize (Zea mays L.) to potassium deficiency. Journal of Integrative Agriculture, 2016; 15(4): 785-794.

[4] Lam V P, Kim S J, Lee H J, Park J S. Root pruning increased bioactive compounds of hydroponically-grown Agastache in a greenhouse. Horticulture, Environment, and Biotechnology, 2019; 60(5): 647-657.

[5] Jing D W, Liu F C, Wang M Y, Ma H L, Du Z Y, Ma B Y, et al. Effects of root pruning on the physicochemecal properties and microbial activities of poplar rhizosphere soil. Plos One, 2017; 12(11): 1-17.

[6] Guan D H, Mahdi M K, Zhang Y S, Duan L S, Tan W M. Tillage practices affect biomass and grain yield through regulating root growth, root-bleeding sap and nutrients uptake in summer maize. Field Crops Research, 2014; 157: 89-97.

[7] Li B, Gu S, Chu Q, Yang Y L, Xie Z J, Fan K J, et al. Development of transplanting manipulator for hydroponic leafy vegetables. Int J Agric \& Biol Eng, 2019; 12(6): 38-44.

[8] Liao R W, Liu J M, An S Q, Niu J L, Liang H, Ren S X, et al. Monitor of corn root growth in soil based on minirhizotron technique. Transactions of the CSAE, 2010; 26(10): 156-161. (in Chinese)

[9] Le Z Y, Liu J M, Liao R W, Bai Y M, An S Q, Guan H. Effect of soil 
temperature and humidity on different developmental periods of corn root. Journal of Maize Sciences, 2013; 21(6): 68-72. (in Chinese)

[10] Xu Z H, Liang M L, Lu D X, Liu M, Liu P, Dong S T, et al. Effect of cutting roots vertically at a place with different horizontal distance from plant on yield and grain storage capacity of summer maize. Acta Agronomica Sinica, 2016; 42(12): 1805-1816. (in Chinese)

[11] Zhang R F, Yang H S, Gao J L, Zhang Y Q, Wang Z G, Fan X Y, et al. Effect of subsoiling on root morphological and physiological characteristics of spring maize. Transactions of the CSAE, 2015; 31(5): 78-84. (in Chinese)

[12] Ayling S M. The growth, yield and nutrient uptake of winter wheat following root-pruning. Annals of Applied Biology, 1989; 114: 567-577.

[13] Wang Z, Su G G, He S L, Shi L Y, He D, Shang W Q, et al. Effects of root pruning on adventitious root formation, enzyme activities, and hormone levels in Paeonia suffruticosa 'Fengdanbai' seedlings. Horticultural Science \& Technology, 2021; 39(1): 10-22.

[14] Hu C L, Sadras V O, Lu G Y, Zhang R Z, Yang X Y, Zhang S L. Root pruning enhances wheat yield, harvest index and water-use efficiency in semiarid area. Field Crops Research, 2019; 230: 62-71.

[15] Li S P, Bi Y L, Yu H Y, Kong W P, Feng Y B, Qin Y F. Simulation on reliefing negative influence of damage roots on growth of maize by application of arbuscular mycorrhizal fungi. Transactions of the CSAE, 2013; 29(23): 211-216. (in Chinese)

[16] Marler T E. Repetitive pruning of Serianthes nursey plants improve transplant quality and post-transplant survival. Plant Signaling \& Behavior, 2019; 14(8): 1621246. doi: 10.1080/15592324.2019.1621246.

[17] Huang Y M, Song F, Wang C, Yao J L, Wang Z J, He L G, et al. Effects of root pruning on growth and expression of related genes in Poncirus trifoliata. Acta Agriculturae Zhejiangensis, 2021; 33(2): 270-277. (in Chinese)

[18] Gao K, Zhu T X, Wang L, Gao Y. Effects of root pruning radius and time on yield of tuberous roots and resource allocation in a crop of Helianthus tuberosus L. Scientific Reports, 2018; 8(S2): 1281-1291.

[19] Mashamaite C V, Dube Z P, Phiri E E. Chemical root-pruning of Moringaoleifera for improved seeding growth. South African Journal of Botany, 2020; 129: 155-160.

[20] Niu H, Bian C J, Long A G, Wang Z L, Cao M, Luo J. Impacts of root pruning and magnetized water irrigation on the phytoremediation efficiency of Celosia argentea. Ecotoxicology and Environmental Safety, 2021; 211: 111963. doi: 10.1016/j.ecoenv.2021.111963.

[21] Vysotskaya L B, Kudoyarova G R, Veselov S, Jones H G. Unusual stomatal behavior on partial root excision in wheat seedlings. Plant, Cell and Environment, 2003; 27(1): 69-77.

[22] Lu D X, Xu Z H, Liu M, Liu P, Dong S T, Zhang J W, et al. Effect of vertically cutting roots at different horizontal distances from plant on leaf photosynthetic characteristics and yield of summer maize with different root types. Scientia Agricultura Sinica, 2017; 50(18): 3482-3493. (in Chinese)

[23] Li Y, Zhao J H, Yan F J, Sun Y J, Li N, Xu H, et al. Effects of root pruning on physiological characteristics and growth of hybrid rice seedlings. Hybrid Rice, 2015; 30(5): 45-53. (in Chinese)

[24] Feng Y T, Lu G Y, Hu C L, Sun Y M. Effects of spring root pruning on yield and flag leaf photosynthetic characteristics of winter wheat under straw mulching. Journal of Triticeae Crops, 2021; 41(6): 738-744. (in Chinese)

[25] Ma S C, Xu B C, Li F M, Liu W Z, Huang Z B. Effects of root pruning on competitive ability and water use efficiency in winter wheat. Field Crops Research, 2008; 105(1-2): 56-63.

[26] Ma S C, Li F M, Xu B C, Huang Z B. Effect of lowering the root/shoot ratio by pruning roots on water use efficiency and grain yield of winter wheat. Field Crops Research, 2010; 115(2): 158-164.

[27] Ma S C, Li F M, Yang S J, Li C X, Xu B C, Zhang X C. Effects of root pruning on non-hydraulic root-sources signal, drought tolerance and water use efficiency of winter wheat. Journal of Integrative Agriculture, 2013; 12(6): 989-998.

[28] Dong G J, Liu W Z. Effect of cutting spring wheat roots on the photosynthesis and the water use efficiency. Chinese Journal of Eco-Agriculture, 2004; 12(2): 77-79. (in Chinese)

[29] Zhang H, Cui L N, Meng J J, Zhang H Y, Shi D Y, Dong S T, et al Effects of partial root excision on the growth, photosynthesis, and antioxidant enzyme activities of maize under salt stress. Chinese Journal of Applied Ecology, 2012; 23(12): 3377-3384.

[30] Wang W J, Wang W P, Jia H L, Zhuang J, Wang Q. Effects of seed furrow liquid spraying device on sowing quality and seedling growth of maize. Int J Agric \& Biol Eng, 2019; 12(2): 68-74.

[31] Mucha J, Jagodzinski A M, Butaj B, Takomy P, Talaska A M, Olyksyn J, et al. Functional response of Quercusrobur L. to taproot pruning: a 5-year case study. Annals of Forest Science, 2018; 75: 22. doi: 10.1007/s13595-018-0708-8.

[32] Cai S W, Liu W Z, Li Y Y. Effect of root cutting on leaf photosynthesis rate and water use efficiency of maize. Chinese Journal of Applied Ecology, 2002; 13(12): 1716-1718. (in Chinese)

[33] Ma S C, Li F M, Xu B C, Huang Z B. Effects of root pruning on the growth and water use efficiency of winter wheat. Plant Growth Regul, 2009; 57: 233-241.

[34] Li Y H, Li Y, Yan F J, Sun J W, Zhao J H, Li N, et al. Effects of seedling-age and root-cutting on growth characteristics and grain yield of hybrid rice. Hybrid Rice, 2016; 31(3): 50-57. (in Chinese)

[35] Liu S Q, Song F B, Wang Y. Correlations between characters of roots and those of aerial parts of maize varieties. Journal of Jilin Agricultural University, 2007; 29(1): 1-6. (in Chinese)

[36] Du Z Y. Research status of root pruning on growth and development in crop. Anhui Agricultural Science Bulletin, 2011; 17(3): 50-51, 94. (in Chinese)

[37] Brandon M M, William R G. Root pruning and auxin alter root morphology of hickories, 2019; 54(9): 1517-1520.

[38] Xu D Y, Miao J H, Yumoto E, Yokota T, Asahina M, Watahiki M YUCCA9-mediated auxin biosynthesis and polar auxin transport synergistically regulate regeneration of root systems following root cutting. Plant \& Cell Physiology, 2017; 58(10): 1710-1723.

[39] He F, Hou Y, Li K, Wei X M, Liu Y Q. Investigation of a root zone heating system for greenhouse seedling and its effects on micro-environment. Int J Agric \& Biol Eng, 2020; 13(6): 47-52.

[40] Pramanik P, Phukan M, Ghosh S, Goswami A J. Pruned tea bushes secrete more root exudates to influence microbiological properties in soil. Archives of Agronomy and Soil Science, 2018; 64(8): 1172-1180.

[41] Ramon A S, Alexandre C X, Evandro C O, Fabio L O, Diego M N, Savio S B. Calibration and validation of FAO-AquaCrop model to estimate the total biomass and yacon root yield. Int J Agric \& Biol Eng, 2020; 13(3): 123-128.

[42] Feng Y J, Jin Q, Wang J W. Systemic induced effects of mechanical wounding on the chemical defense of Bt corn (Zea mays). Chinese Journal of Plant Ecology, 2010; 34(6): 695-703. (in Chinese)

[43] Fang Y, Xu B C, Turner N C, Li F M. Does root pruning increase yield and water-use efficiency of winter wheat? Crop \& Pasture Science, 2010; 61: 899-910.

[44] Aldahadha A M, Warwick N W M, Backhouse D. Effects of pythiumirregulare and root pruning on water-use efficiency of hydroponically growth wheat under PEG-Induced drought. Journal of Phytopathology, 2012; 160(7-8): 397-403.

[45] Xu Z H. Effect of cutting root vertically at different horizontal distance on grain development and yield of summer maize. Master dissertation. Tai'an, China: Shandong Agricultural University, 2016; 54p. (in Chinese) 